\title{
The systems psychodynamic experiences of professionals appointed in acting capacities
}

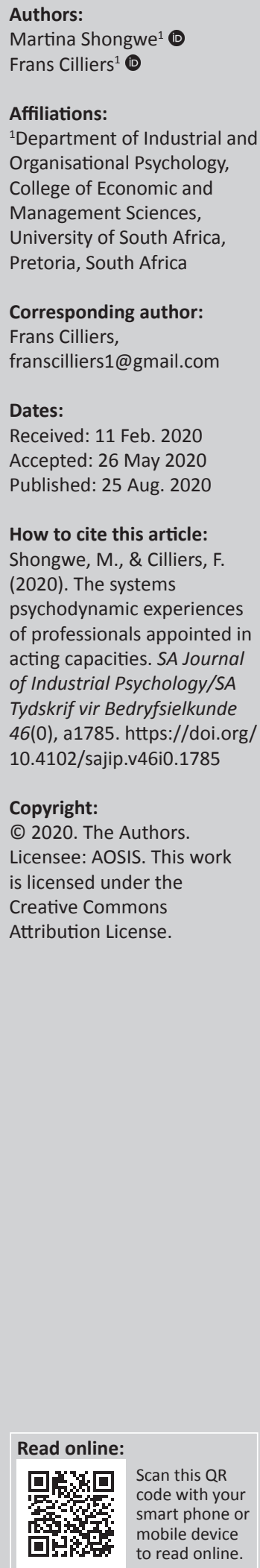

Orientation: During times of organisational change and restructuring, employees are often placed in acting capacities. The unconscious experiences and systemic impact thereof have not been researched in South Africa or globally.

Research purpose: The research aim was to report on the systems psychodynamic lived experiences of professional employees functioning in acting capacities for an extended period of time.

Motivation for the study: Consciously, the appointment of acting staff serves the restructuring agenda by testing change endeavours. Unconsciously, they may become representatives of change and containers of systemic anxiety.

Research design, approach and method: A qualitative and descriptive research approach was undertaken using five participants as collective case study. Data were gathered through interviews and hermeneutically analysed.

Main findings: The manifesting themes were conflict, anxiety, task, role, boundary, authorisation and identity. Further interrogation of the data revealed the interrelated aspects of becoming containers of systemic toxicity, employment and psychological contracts being violated, being placed on hold, seduced, bullied and traumatised.

Practical/managerial implications: A dysfunctional organisation experiencing anxiety about restructuring, manifesting as incompetence, emotion turmoil and systemic toxicity, (unconsciously) projected its anxiety into professionals in acting capacities, who became the containers of the toxicity. The symptoms (anxiety) as well as the cause (restructuring) need to be studied and addressed.

Contribution/value add: This research illustrated how professionals in acting capacities were unconsciously used to perform the emotional labour related to change and became the unconscious containers of larger systemic dynamics, specifically about the anxiety of change and restructuring.

Keywords: acting; unconscious behaviour; professionals; anxiety; defences; organisational toxicity; bullying.

\section{Introduction}

Organisational change endeavours (Cummings, Worley, \& Donovan, 2020; Viljoen, 2015) are operationalised as structured processes towards the optimisation of the organisation as a whole. The conscious impact of such processes has been well reported in terms of human resources management practices in general (Wangithi \& Muceke, 2012), and specifically in restructuring (Soni, 2016), downsizing (Sitlington \& Marshall, 2011), re-engineering (Sikora, Moore, Greenberg, \& Grunberg, 2008) and demotion and retrenchment (Botes, 2014). However, the unconscious impact of such change endeavours seems to be under-researched. Studies on redundancy (Sher, 2013, 2017) and bullying (White, 2013) reported these two organisational phenomena to be attacks on both employment and the psychological contract. Impacted employees manifest with symptoms of extremely high levels of survival and performance anxiety, an array of defence mechanisms, a struggle with adjusting their psychological contract, as well as negative climate implications for the organisation as a macro system (Armstrong \& Rustin, 2015; Sher, 2017). Related to the above-mentioned organisational practices is the appointment of employees in acting capacities. Apart from comments in newspapers (Basson, 2013; Ross \& Gerstenzang, 1989), only one research article could be traced that quantitatively studied the conscious impact of organisational acting (Emewu, 2013). The results show that employees are often kept in acting capacities for extended periods of time, without official 
structures in place governing work content or acting tenure, that their workflow and career progress are disrupted and that they are treated as temporary workers. No research evidence about the unconscious impact of prolonged acting could be found.

\section{Research purpose and aim}

The research question was formulated as follows: what is the unconscious impact on employees who are appointed in an acting capacity for an extended period of time without official support structures? The research aim was to report on the systems psychodynamic lived experiences of professional employees functioning in acting capacities for an extended period of time. The contribution of this research lies in providing an understanding of the depth psychology involved in studying organisational acting, and how industrial and organisational (IO) psychologists and coaches may approach consultations to this phenomenon. In the discussion, the qualitative themes are interrogated in terms of their systemic inter-relationships.

\section{Literature review}

The Public Services Act of 1994 (Republic of South Africa, 1994) makes provision for government departments in the Department of Public Service and Administration (DPSA) to place employees in acting capacities, described as a vacant position where an employee from a lower level acts for a period of time. This provision addresses the (conscious) regulation of time frame as well as the remunerative aspects of the acting capacity. It seems that the act is addressing adjustments in the employment contract in terms of input, output and reward, which could relate to employees' conscious behaviour in terms of motivation, commitment and organisational citizen behaviour (Anggraeni, Dwiatmadja, \& Yuniawan, 2017; Shapiro, 2020).

Acting impacts the employee's psychological contract, especially in terms of unconscious work identity (Dejours, 2015; Kets De Vries, Korotov, \& Florent-Treacy, 2007). This contract is unofficial, unwritten and represents employees' subjective experiences of the self in the workplace (Wangithi \& Muceke, 2012) - an unconscious 'contract-inthe-mind' (Armstrong, 2005). As such, the contract contains subjective anxieties, needs and desires towards authority figures (e.g. to be appreciated, rewarded and cared for by the employer) as well as transferences of past and often unfulfilled childhood emotional experiences brought into the present (De Board, 2014). This serves the ideal self in relation to the idealised organisational system (Armstrong \& Rustin, 2015; Layton \& Leavy-Sperounis, 2020).

In this research, these unconscious behaviours are studied through the systems psychodynamic (SP) lens. Systems psychodynamics originated at the Tavistock Institute for Human Relations in London and functions as a depth psychology organisational theory, consultancy stance and research domain (Cardona, 2020). Systems psychodynamics is informed by Freudian systemic psychoanalysis, group and object relations, and systems thinking (Cytrynbaum \& Noumair, 2004).

Systems psychodynamics studies organisations as consisting of complex micro-, meso- and macro-systems with cognitive, affective, motivational and relational behaviours manifesting consciously and unconsciously (Armstrong, 2005).

The term 'consciousness' refers to rational day-to-day behaviour in the self and in human relations whilst the system performs the sophisticated organisational task. 'Unconsciousness' refers to behaviour that the system is unaware of in its object relations and contains various forms of anxiety, irrationality and defensive structures whilst working on the basic assumption task (Steiner \& Hall, 2017).

Five SP basic assumptions form the basis for the interpretation and understanding of all systemic behaviour (individual, group and organisation) and are therefore relevant to this research. When dependency manifests, it can be interpreted as the system's fantasy that it needs to be rescued by an omnipotent leader out of the difficult acting capacity (Curtis, 2015); fight/flight may indicate the system's experience of being ill-treated by the organisation, followed by the need to fight back against the system and/or to use flight away from the acting capacity by resigning, for example (French \& Simpson, 2015); pairing between part-objects in the system (e.g. acting colleagues and human resources) could indicate the belief that the acting participants' survival depends on this fantasised connection (Gould, Lucey, \& Stapley, 2011); one-ness may manifest where the acting professionals behave as an undifferentiated, homogeneous, omnipotent and powerful yet passive union without individuality, differentiation or diversity; and me-ness may manifest where the acting professionals experience a fear that the organisation's group forces will take away their individuality (Cardona, 2020).

Various SP constructs are relevant to this research, all of which are encapsulated in the boundaries, authority, role, task (BART) (Cytrynbaum \& Noumair, 2004), conflict, identity, boundaries, authorisation, role, task (CIBART) (Cilliers \& Koortzen, 2005), and anxiety, conflict, identity, boundaries, authorisation, role, task (A-CIBART) (Van Niekerk, 2011) models.

Hirschhorn (2018) suggests that all of the above mentioned constructs are supported by an array of other SP constructs. In this research these models were not used as a point of departure - rather the research was inductive in nature (see the 'Research approach' section). From an SP stance it could be hypothesised that professionals appointed in acting positions for an extended period of time could experience several behaviours. Anxiety (seen as the fear of the future and acting as the dynamo of unconscious psychic energy; Curtis, 2015) could manifest in different forms and intensities. The system will defend itself against the anxiety by using 
different individual, social and system domain defensive structures (Armstrong \& Rustin, 2015). Primary task behaviour could be jeopardised and could be replaced by offtask and anti-task behaviour (Steiner \& Hall, 2017. Role confusion could impact the normative (the measurable work content), existential (the system's introjections about its performance) and phenomenal (the system's received projections by the other) levels. If a significant difference is experienced between these three levels, the system's anxiety could increase (Obholzer \& Roberts, 1994). This will especially be significant amongst parts of the system with a valence for projections of incompetence (Shapiro, 2020). Next, the system may experience anxiety connected to ineffective boundary management, which in turn will lead to a sense of being deauthorised (Hirschhorn, 1997). All of the above experiences could lead to the system's identity being under attack (Layton \& Leavy-Sperounis, 2020).

\section{Research design \\ Research approach}

A qualitative and descriptive research approach was used in this study, following the psychosocial tradition (a cluster of methodologies from a distinct position of researching unconscious communication, dynamics and defences beyond the purely discursive) (Clarke \& Hoggett, 2009). Hermeneutic phenomenology was used as the interpretive stance in order to study the lived experiences of professionals in acting capacities as a research phenomenon. The research was grounded in a constructivist, interpretive epistemology based on the assumption that participants' perceptions and understanding of meaning ascribed to their experiences form their reality (Thorne, 2016). The research was inductive in nature, namely, focussing firstly on the understanding of lived experiences, and then as part of double hermeneutics interpreting the behaviour from the relevant literature (Terre'Blanche, Durrheim, \& Painter, 2006).

\section{Research strategy}

A collective case study (Wilson \& MacLean, 2011) of professionals in one organisation was used. The unit of analysis was the collective group of participants, congruent to the SP assumption that the individual (micro-level) behaves on behalf and as a representation of the group (macro level; Cytrynbaum \& Noumair, 2004). This strategy served an intrinsic (towards understanding) and instrumental (providing information to the organisation) purpose (Gergen, Josselson, \& Freeman, 2015).

\section{Research method Research setting}

The research was conducted in a South African public service organisation in the Safety and Security Cluster. Before and during the research, the organisation had been involved in a long period of organisational change.
Restructuring was implemented to address the duplication of roles and divisions, to streamline the business and to improve efficiency. During this time, some professional members of the management team were appointed in acting capacities, being individually and informally instructed by management to take up 'an acting capacity for the interim'. Although some professionals requested such, these appointments were not informed or supported by a strategy, selection criteria or procedure, time limit, succession plan or individual contract.

\section{Entrée and establishing researcher roles}

The first researcher was employed in this organisation in the role of a psychologist in the Human Resources Department. As a systems psychodynamically informed consultant, she became intrigued by her colleagues' experiences in their acting capacities. She decided to investigate this phenomenon as a formal research project. She was responsible for the literature review and the empirical study. The second researcher took up the role of a research supervisor and took responsibility for the structuring of the article.

\section{Sampling}

Purposive and deliberate sampling was used (Thorne, 2016), focussing on professionals in Corporate Services, originally appointed in senior general manager positions, responsible for strategy implementation, the management of direct reports and who had been in acting capacities for more than 12 months. Data saturation (seen as information redundancy - Thorne, 2016) was reached after five interviews. Saturation was based on the researchers' degree of confidence that the data had been heard so frequently that it could be anticipated, and that the findings had become sufficiently well developed to warrant reporting. Table 1 shows the demographics of the sample of five professionals.

\section{Data collection methods}

Two methods were used for data collection. Firstly, a 90-min socio-analytic interview (Long, 2013) was used, designed congruently to the five SP behavioural assumptions and all related constructs (as mentioned above) and the hermeneutic lens. The purpose of the interview was to study the participants' thoughts, feelings and experiences during their time of being in an acting capacity. Operationally, the interview was unstructured, exploring in-depth SP behaviour, administered and contained in a secure boundary of space (room set-up) and logistics (preparation, appointments and ethics). The interview consisted of an introduction (explaining the purpose of the study, conditions and gaining participant consent), questions and a review of

\begin{tabular}{lllcl}
\hline \multicolumn{2}{l}{ TABLE 1: Demographics of the study sample. } \\
\hline Participant number & Race & Gender & Age & Time acting \\
\hline 1 & White & Female & 52 & 21 months \\
2 & White & Female & 50 & 22 months \\
3 & Black & Female & 50 & 17 months \\
4 & Black & Male & 44 & 20 months \\
5 & Black & Male & 40 & 22 months \\
\hline
\end{tabular}


the conversation. The questions were formulated as follows: 'what were your experiences in your acting capacity during the last 12-18 months in terms of thinking, feeling and doing?' and 'how did that influence your personal and work relationships?' Participants were encouraged to 'think the unknown known' and to access the unconscious infinite (Bion, 1961). The interviewer's role was demarcated as to observe, listen actively, clarify, challenge, empathise through reflection of feelings and encourage free association. Secondly, data were collected by means of interviewer field notes (Wilson \& MacLean, 2011). This included impressions, perceptions, body language and non-coincidences concerning the participants' and researcher's behaviour, manifesting before, during and after each interview. The interviews took place in a boardroom, were audio-recorded and transcribed. The researcher notes were integrated with the recorded data.

\section{Strategies employed to ensure data quality}

Various elements of trustworthiness were ensured (Graneheim \& Lundman, 2003; Johnson \& Waterfield, 2004; Sekaran \& Bougie, 2018; Terre'Blanche et al., 2006; Thorne, 2016). Credibility was ensured by adopting methods that are well established in socio-analytic and SP qualitative research. The researchers are trained in the SP stance including using themselves as the primary instruments of analysis and interpretation. Triangulation was applicable in the use of two types of methods of data analysis.

Transferability was ensured by identifying the context within which the study was conducted and its salient features. This was limited by the arguments about the sensitivity of the primary task of the organisation and its employees. The researchers invited the readers (psychologists, managers and leaders in acting capacities) to explore the relevance of the findings to their own experiences in their organisations. Dependability was ensured through the clear formulation of research questions congruent to the aims, design and method of the study. The findings were presented following a clear and consistent pattern that facilitates access and clarity to the readers, professionals and academics. The researchers had the data and interpretations scrutinised by another psychologist trained in SP and qualitative research. The procedure was to work through samples of raw data, themes, interpretations and the conclusion. The psychologist testified to the dependability and saturation of the findings. To ensure confirmability, steps were taken to ensure that the findings were the result of the experiences and ideas of the participants, rather than the characteristics and preferences of the researcher. This included a periodic SP reflective processing by the researchers of their emotional involvement, conscious and unconscious conflicts, bias and representation in the research - for example, the first researcher's double role of being an employee of the organisation and the researcher (Clarke \& Hoggett, 2009; Gergen et al., 2015; Thorne, 2016).

\section{Ethical consideration}

Ethical clearance was granted by the university, as well as the organisation. Ethicality was ensured through privacy, informed consent, confidentiality, respecting of rights, not causing harm and ensuring transparency in the usage of data.

\section{Data analysis}

Data analysis was guided by phenomenological reduction, seeing text as a metaphor for a social phenomenon (Alvesonn \& Sköldberg, 2010) and reification (referring to human phenomena as if they are things) (Clarke \& Hoggett, 2009). Simple hermeneutics allowed for the understanding of the content of participants' experiences in their acting capacities, and double hermeneutics allowed for the critical interpretation of their experiences from the SP stance (Clarke \& Hoggett, 2009). This included the analysis of the participants' normative (content), existential (introjected) and phenomenal (projected) roles (Obholzer \& Roberts, 1994). The interpretation of the data took the hermeneutic circle into account (Alvesonn \& Sköldberg, 2010). This implies that the individual participant's unique experiences were interpreted in relation to their significance in the collective case study.

\section{Reporting style}

The findings are reported per theme. In the discussion, Thorne's (2020) guidance on the reporting of qualitative data was followed. This entails that, instead of merely reporting on themes, a process of genuine discovery through depth (psychology) analysis was followed-a thorough interrogation of the intellectual complexity of the data, a critical reflection on its inter-relationships, thoughtful examination of possible interpretations and insightful reporting. For this collective case study, individual verbatim responses are given where appropriate and integrated responses representative of the whole sample elsewhere.

\section{Findings}

Seven themes manifested, namely, conflict, anxiety, task, role, boundary, authorisation and identity, all related to the BART/CIBART / A-CIBART models.

\section{Theme 1: Internalised conflict}

Participants' conflict manifested on the intrapersonal, interpersonal and intragroup levels. Intrapersonal conflict manifested in being emotionally trapped, as shown in the following statements: 'I want to resign, but I cannot' and 'I feel needed and maybe I am living in a fool's paradise'.

Interpersonal conflict manifested between the self and family - on the one hand to censor and keep troublesome experiences away from family members (e.g. 'one carries the burden inside of yourself and just communicate what you think your husband can digest'), and on the other hand to use family members as confidantes (using partners and friends as buffers 'on a daily basis to offload stress'). 
Intragroup conflict manifested in the entire management team where the acting managers became known as 'the newly promoted group' who had to 'earn the respect of others and live up to their level'. The conflict of being accepted by the system or not was internalised, leading to self-doubt and poor self-esteem ('one has conflicts within oneself and it unconsciously affects the self'). The experience of these conflicts negatively influenced participants' behaviour towards functioning as good organisational citizens (the struggle to be 'more committed', 'disciplined', 'time conscious' and 'arriving for meetings first and on time!'). They experienced distance between themselves and their direct reports (who became 'negative' and 'non-cooperative').

\section{Theme 2: Debilitating anxiety}

Participants experienced high levels of neurotic anxiety (Newton, Long, \& Sievers, 2006). Persecutory anxiety manifested in their experience of being under attack by the system based on the fear of losing the desired object (Curtis, 2015) (e.g. 'a successful career', 'dignity', 'competence', 'rationality', 'identity' or 'sanity'). Depressive anxiety followed from their fear of not being good enough for the loved object (the organisation and its authority figures) and the ambivalence in feeling both attachment to and detachment from them (Prior \& Glaser, 2006). Although the focus is expressed towards the external ('what this organisation is doing to $\mathrm{me}^{\prime}$ ), it originates from the internal and unconscious wish to aggressively attack the unmanageable destructive forces. Performance anxiety manifested in their sense of not being good enough ('unqualified', 'not having the right personality') to be permanently appointed. Their high levels of anxiety led to irrational thinking in their attempt to resolve the complex emotions - it felt as if 'I was losing my hold on life'.

Their defence mechanisms served to protect themselves (Blackman, 2004) from being overwhelmed and humiliated. These were repression (e.g. 'I never told anyone about how I feel'), reaction formation ('pretending that all is well'), regression (becoming overly 'dependent on feedback' from authority figures), sublimation (of fear and anger with 'trying to understand' the organisation's rationale), denial (an attempt to 'change the status quo' and to refuse facing the reality of their position and state of mind) and displacement (of the 'anger towards the self' for 'accepting the acting position', and projecting this onto the organisation). They became detached from their authentic experiences (Armstrong \& Rustin, 2015), which disturbed them greatly they felt helpless.

\section{Theme 3: Stuck in task}

Consciously, the participants described their primary task (Cytrynbaum \& Noumair, 2004) in a linear and mechanistic manner by focussing on their responsibility and managing their subordinates to reach performance targets. They experienced a 'stuckness' (e.g. 'I have to do as requested and not to question the wishes of my seniors'), helplessness and hopelessness ('tasks are given - nothing is gonna change for $\mathrm{me}^{\prime}$ ).

They denied the pain about their competence not being recognised and fantasised about and idealised 'being promoted someday' as recognition of their 'competence as a manager'.

\section{Theme 4: Role confusion}

Participants were mostly clear regarding their normative roles as communicated directly to them or in how they had learnt through experience what the role was supposed to entail.

In their existential role (Newton et al., 2006), they experienced uncertainty, confusion ('how confusing, totally confusing!'), mostly related to the undefined period of acting, a deep sense of betrayal and shame, all connected to their high level of performance anxiety. This anxiety caused ambiguity. On the one hand, they idealised 'the senior role' with its 'promise of promotion'. On the other hand, they were apprehensive, felt seduced by the system and even 'punished for not being competent' and good enough. These experiences reflected their persecutory anxiety as a reflection of their internal loneliness and isolation (Kets De Vries et al., 2007).

In their phenomenal role (Obholzer \& Roberts, 1994), they received projections from their superiors and subordinates about not fulfilling the role to the expectation. The data showed evidence of projective identification - how they took in the projections and acted out what others thought of them and their performance.

\section{Theme 5: Anxiety on the boundaries}

Various boundaries impacted the participants. Practically, some participants had crossed a geographical boundary by having had to physically relocate, leaving 'home' and 'family' elsewhere. Their interpersonal boundaries with colleagues, family and friends changed significantly - they were 'hesitant to share their experiences' with others in 'fear of feeling incompetent' and coming across as 'troubled by work matters'.

Time boundaries caused survival anxiety in 'not knowing for how long' they would stay in the acting capacity.

In terms of role, the greatest issue was the crossing of the boundary from the 'actual' to the 'assumed' role.

These boundary shifts, crossings and blurring created an almost unbearable motivational anxiety (Steiner \& Hall, 2017).

\section{Theme 6: De-authorisation}

Participants experienced being de-authorised from above and below (Hirschhorn, 1997). They received projections of 
incompetence, which (through projective identification) they absorbed (Blackman, 2004), thus experiencing self-doubt and performance anxiety. This had a negative impact on their task performance and team contributions. Initially, participants experienced being acknowledged and trusted by the organisation and leadership to take on a more senior position. Later, they realised that leadership was not officially supporting them with performance agreements or discussion about their future roles or careers and generally treated them with disrespect (e.g. 'as if we were forgotten by the system'). From below, participants experienced being de-authorised by subordinates - they 'collude against' 'acting managers', 'withhold important information', 'act with disrespect' and 'sarcasm'. It was as if they were envious towards what the participants represented (Huffington, Armstrong, Halton, Hoyle, \& Pooley, 2004). This resulted in participants' heightened persecutory anxiety (e.g. 'as if people are against me').

\section{Theme 7: Identity under attack}

Participants' identities were under attack, which resulted in 'living in splits' to the point of feeling fragmented.

As employees, they reported on how they knew where they were coming from (being sure about their past career aspirations and experiences), confused, unstable and insecure in their present acting capacities, and uncertain about their future in the organisation. They referred to an 'old' and a 'new' organisation, which represents the splits between truth and rationality versus what is irrational and a bad fantasy. This manifested as survival anxiety, followed by defences such as compensation and reaction formation (they became compulsive about detail and structures). Informally, they were not referred to by their professional and organisational titles anymore - instead, they were referred to as 'acting' and 'interim'. It was as if colleagues framed them as without role boundary (job description) or contract. Participants experienced this as being professionally de-authorised, shamed and denigrated, stripped of their professional status. This was also experienced as retraction of recognition from significant authority figures (Lewis, 1971).

Participants showed signs of narcissistic injury or woundedness (Gaitanidis \& Curk, 2007), which are evident in the following statements: 'I have to navigate through a situation and get people to accept that I can offer a better service' and 'I had been in management for 16 years. In a snap of fingers my management was taken away'.

This was interpreted as their professional boundaries being under attack, which led to fragmentation beyond the paranoid-schizoid position (White, 2013). As human beings, these experiences negatively influenced their personal lives, as shown in the following statement: 'You know, I am defined by my work; when you take away my work, you take my life'.
Their confusion manifested in conflict between their real, ideal and denigrated selves. No research could be traced referring to the professional identities of acting staff.

\section{Discussion}

The research aim of this article was to report on the SP lived experiences of professional employees functioning in acting capacities for an extended period of time. In this discussion, the experiences related by the individuals (representing the micro-system) will be explored further in terms of its relatedness (Cardona, 2020) to the organisational dynamics (representing the macro-system).

The seven themes illustrated that on the individual systemic level, the findings revealed the acting professionals' identities to contain experiences of personal and social conflict; high levels of neurotic anxiety followed by an array of defences for self-preservation; a stuckness, hopelessness and helplessness in the execution of their primary task; anxiety in managing their space, time and role boundaries and de-authorisation, all adding to an experience of their employee and professional identities being under attack. Next, these findings are interrogated in terms of the psychodynamic complexity and inter-relationships (Thorne, 2020) towards the understanding of the impact of acting on the organisational level. The data evidenced that the organisation positioned (Campbell \& Groenbaek, 2006) acting professionals as containers of systemic toxicity, where their employment and psychological contracts were violated, and where they were placed on hold, seduced, bullied and traumatised (Allcorn \& Stein, 2015; Diamond \& Allcorn, 2009; Gould et al., 2011; Shapiro, 2020).

\section{Containers of systemic toxicity}

Evidence suggests that this organisation did not function as a competent system (Hodgkinson \& Sparrow, 2002) in terms of strategic and knowledge management, cognitive behaviour (rationality and objectivity in decision-making), emotional intelligence and sense making (being emotional attuned) or an internal motivation (locus of control). Furthermore, the organisation showed evidence of managerial mismanagement and toxicity (Allcorn \& Stein, 2015; Lubit, 2004), characterised by irrational decisionmaking, ('misuse of power', 'playing [of] political games'), emotional violence ('intolerance', 'distrust' and 'disrespect') and narcissism (Gaitanidis \& Curk, 2007). The organisation's primary defence mechanism was the splitting of the good from the bad, owning the good ('want to be seen as competent') and projecting the bad onto and into (through projective identification - Blackman, 2004) the professionals in acting capacities, who acted out the toxicity in the following behaviours. They experienced psychosomatic symptoms (e.g. 'choking at night', 'I thought I am getting a heart attack', 'I had a stroke' and 'I feel drugged most of the time'), not being understood ('what happens in this place does not make sense'), fear (of doing wrong as well as of 
psychological toxic contamination), distancing (e.g. 'I started to share less and less') and paranoia (e.g. 'the organisation is a political one which treads on power' and 'a powerful small group are really in charge of this organisation'). The findings on behaviour in toxic organisations reported by Allcorn and Stein (2015), Goldman (2008) and Lipman-Blumen (2005) revealed some of these symptoms but described in terms of consciously experienced stress.

\section{Violation of employment and psychological contracts}

The professionals' employment contract was violated in terms of boundaries. The time boundary was not specified, the acting policy was ignored and working conditions were not discussed with incumbents. The task boundary was and stayed unclear, no performance contracts were given and for some no acting allowance was paid. This implied the violation of the psychological contract, where professionals experienced being bullied and 'not looked after'. This contributed to their unbearable free-floating anxiety (White, 2013). They tried to cope by focussing on the task at hand (as evident in the quotes, 'do what I can within my area of control and that is where it ends', 'anything outside of my area of control I let go off', 'in the interest of the organisation and for my own sanity' and 'let me just continue to do the work') whilst also experiencing hopelessness and helplessness (realising that 'this does not work for me' and 'this is making me sick'). This relates to the experienced attack on their professional identities. Previous research on the psychological contract did not study unconscious behaviour (Anderson \& Schalk, 1998; Briner \& Conway, 2006; Wangithi \& Muceke, 2012). Anggraeni et al. (2017) report on how the psychological contract can contain commitment and organisational citizenship from a positive psychology stance. Syed's (2010) research described the impact of restructuring on the psychological contract, but related to conscious attitudes (without reference to unconscious behaviour).

\section{Being placed on hold}

At the time of this study, South Africa as a contextual macrosystem experienced being placed on hold (Basson, 2013). There was a lack of leadership and no indication that anything was being done to resolve problems about service delivery protest actions, salary negotiations and burning national education and health matters. As a subsystem (Kets De Vries et al., 2007), this public service organisation experienced the same frustration, manifesting as a lack of performance and placing managers in acting capacities for indefinite periods of time, as shown in the following statement: 'This is very weird - the Minister extended my acting capacity indefinitely'.

These professionals referred to 'being placed on hold', disconnected from leadership's awareness. This was interpreted as the professionals in acting capacities experiencing, representing, holding and acting out the larger system's anxiety, as revealed in the following statements:
'You are kept in an unstable, uncertain state the whole time' and 'No further communication was provided and that was the end of the discussion'.

It was as if the only escape from being 'on hold' was to get out ('the system can use you' and 'get rid of you'). A larger systemic interpretation is that the system unconsciously used the 'acting' role as a holding space for its collective survival anxiety, with the professionals processing the survival pain (Winnicott, 1965). This view of how individuals contain behaviour on behalf of the organisation is well known in SP (Cytrynbaum \& Noumair, 2004), although no research evidence exists on what is contained in acting capacities.

\section{Seduction}

Professionals were 'handpicked' for their acting capacities. This act was experienced as something 'intimate' and 'secret' that made them 'feel special'. After a while they realised that this was a strong authoritative drive (cold and manipulative), which made them feel betrayed and suspicious, as clearly expresed in the following statements: 'He lied to me', and 'I can deal with that, but allow me to know the truth communicate with me'.

They experienced being 'set up' in a reward-punishment dynamic - success was promised with a demand for loyalty and a threat that betrayal would be punished (e.g. 'this injustice is wrong, painful'). These experiences left the professionals being hurt and distrusting the system. This was interpreted as organisationally unethical and, in terms of relationships, seductive (Cytrynbaum \& Noumair, 2004). This caused injury and paranoia in the system and moreover made these professionals the containers ('dumping ground') of systemic 'injustice'. No other empirical research evidence related to acting roles could be found to confirm this hypothesis.

\section{Bullying}

Professionals were denigrated and belittled. Examples include: In meetings 'you must explain decisions taken at levels that you have no control over' and 'Managing projects totalling R54 million, I got a call from Exco telling me there is no toilet paper and the car park is dirty'.

They became unable to relate to their environment, struggled to make sense of events and experienced confusion, uncertainty and a lack of meaning. In spite of their 'perseverance', they 'felt forced' ('although this is not like $\mathrm{me}^{\prime}$ ) to let their fear take over ('no one touches destructive, nasty people' - 'they fight back') leading to the professionals' withdrawal (with an 'inability to fight' and 'taking a backseat'), whilst staying loyal ('I continued to give my best'). Although they experienced anger and resentment, they responded with 'sucking up' and hoping the situation would pass. Some slept 'for a good straight $36 \mathrm{~h}$ over weekends'. This was interpreted to mean that the professionals' strong flight response (Cytrynbaum \& Noumair, 2004) indicated that they had become victims of 
systemic bullying, where, through projection, the fear was locked into them to contain and keep silent on behalf of the system. This dynamic resembles the organisational bullying reported by Cilliers (2012) and White (2013).

\section{Traumatisation}

Professionals were forced to stay in their acting capacities for a long time without any opportunity to be rationally listened to or to process their experiences. They experienced emotional pain, humiliation, devastation, being out of control, high levels of survival and performance anxiety, and illustrated intense defensive behaviour such as denial, introjection and repetition compulsion (Blackman, 2014). It was interpreted that these professionals suffered from emotional trauma, which is echoed by research cited by Curtis (2015).

\section{Practical and managerial implications}

If industrial and organisational psychologists were not aware of the unconscious systemic dynamics manifesting in organisations, the behaviour of these professionals may have been interpreted (e.g. from an individual psychology perspective) as 'non-coping' with demands or stress, followed by a decision about their incompetence and non-promotability to the positions they had been acting in. On the other hand, SP argues that the individual experiences do not only belong to the individuals but also to the whole organisational system. This research illustrated how an organisation experiencing high levels of anxiety during restructuring may project the dark side of the experience onto a group of staff members who then become the containers of systemic toxicity. Furthermore, through study by systems psychodynamically informed industrial and organisational psychologists of the manifesting unconscious behaviour of individuals and its relatedness to the organisation's dynamics, a richness of psychological data becomes available. These data can be used to coach the employees in acting capacities to self-authorise and to consult with the organisation to become aware of the levels of anxiety and their impact on the total system (Campbell \& Groenbaek, 2006).

\section{Limitations and recommendations}

The literature on acting as an organisational phenomenon is very limited. This made comparison to other research findings almost impossible. Especially in terms of unconscious manifestations, the researchers had no benchmark to compare and assess the findings and interpretations. We can only hope that our empathic listening, analysis and recording of participants' lived experiences did justice to their very anxiety-provoking situation.

More research, on both the conscious and unconscious experiences of being in acting capacities, is needed in order to study the different types of organisations and motivations for using this practice. Industrial and organisational psychologists, in their consulting and coaching roles, should be sensitised towards clients' emotional labour and its experienced unconscious manifestations, especially during change endeavours when systemic anxiety increases. Being placed in an acting capacity is just one example of how organisations project onto subgroups.

\section{Conclusion}

On the organisational and conscious levels, this organisation and its leadership started a change endeavour, applying restructuring as a method. When faced with the dark and messy aspects of change, dependence, survival and performance anxiety manifested. The organisation's collective unconscious defended the system against anticipated failure and pain by resisting and avoiding the change and suppressing the restructuring anxiety. To contain the anxiety, a container for the discomfort was found in a subsystem of professionals on senior general manager level responsible for strategy implementation. This subgroup had the non-coincidental valence to be positioned as this container because of their primary organisational task (implementing strategy). This may have represented one-ness. The unconscious task of the container would be to, through projection and projective identification, hold the system's restructuring anxiety with the messianic fantasy that it will process the organisation's change initiative. This is an impossible task because it is based on a fantasy, and no authorisation is given to the role. In order to make the subgroup visible, acting capacities were created. The targeted professionals interpreted their new roles as a reward for performance and a promise of future career possibilities. Instead, the acting capacities became the representational object of change, targeted by toxicity and bullying tactics. The incumbents in the newly created subsystem were seduced and bullied into experiencing this trauma, thus acting out the system's dark side. The organisation putting the subgroup on hold (forgetting about it) serves as an avoidance tactic to not work with its own dark side. The professionals' experienced identity crisis serves as a mirror of the organisation's identity crisis as it is being restructured. In this organisation, acting capacity as an unconscious organisational object manifests as a repetitive compulsion, which allows the organisation to stay in denial about the real challenges and may only be stopped through intense systems psychodynamic consultancy to the organisation and coaching for the individuals (see Allcorn \& Stein, 2015; Armstrong \& Rustin, 2015; Gould et al., 2011; Shapiro, 2020).

\section{Acknowledgements Competing interests}

The authors have declared that no competing interests exist.

\section{Authors' contribution}

M.S. performed the literature review and the empirical research. F.C. performed the structuring of the article, the formatting and the academic editing. 


\section{Funding information}

This research received no specific grant from any funding agency in the public, commercial or not-for-profit sectors.

\section{Data availability statement}

Data sharing is not applicable to this article as no new data were created or analysed in this study.

\section{Disclaimer}

The views and opinions expressed in this article are those of the authors and do not necessarily reflect the official policy or position of any affiliated agency of the authors.

\section{References}

Allcorn, S., \& Stein, H.F. (2015). The dysfunctional workplace. Theory, stories and practice. Columbia, IN: University of Missouri Press.

Alvesonn, A., \& Skoldberg, K. (2010). Reflexive methodology. New vistas for qualitative research. Los Angeles, CA: Sage.

Anderson, N., \& Schalk, R. (1998). The psychological contract in retrospect and prospect. Journal of Organisational Behaviour, 19(S1), 637-647.

Anggraeni, A.I., Dwiatmadja, C., \& Yuniawan, A. (2017). The role of psychological contract on employee commitment and organisational citizenship behaviour: A contract on employe cound Indonesian young entrepreneurs in management action. SA Journal of Industrial Psychology/SA Tydskrif vir Bedryfsielkunde, 43(1), a1409. https://doi. Industrial Psychology/SA Tyds
org/10.4102/sajip.v43.0.1409

Armstrong, D. (2005). Organisation in the mind. Psychoanalysis, group relations and organisational consultancy. London: Karnac.

Armstrong, D., \& Rustin, M. (2015). Social defences against anxiety. London: Karnac.

Basson, A. (2013). When will Zuma fill these posts? City Press. Retrieved from https:// www.citypress.co.za/politics/when-will-zuma-fill-these-posts/

Bion, W.R. (1961). Experiences in groups and other papers. London: Routledge.

Blackman, J.S. (2004). 101 Defences. How the mind shields itself. New York, NY: Brunner-Routledge.

Botes, J. (2014). Alternatives to retrenchment. Management opinion South Africa. Retrieved from https://www.bizcommunity.com/

Briner, R., \& Conway, N. (2006). Protecting the psychological contract. Personne Today, 21(11), 28-30.

Campbell, D., \& Groenbaek, M. (2006). Taking positions in the organisation. London: Karnac.

Cardona, F. (2020). Work matters. Consulting to leaders and organisations in the Tavistock tradition. London: Routledge.

Cilliers, F. (2012). A systems psychodynamic description of organisational bullying experiences. SA Journal of Industrial Psychology/SA Tydskrif vir Bedryfsielkunde, experiences. SA Journal of Industrial Psychology/SA Tydskrif
38(2), Art\#994, 11. https://doi.org/10.4102/sajip.v38i2.994

Cilliers, F., \& Koortzen, P. (2005). Working with conflict in teams. The CIBART model. HR Future, October, 52-53.

Clarke, S., \& Hoggett, P. (2009). Researching beneath the surface: Psycho-social research methods in practice. London: Karnac.

Cummings, T.G., Worley, C.G., \& Donovan, P. (2020). Organization development and change. London: Cengage Learning.

Curtis, H. (2015). Everyday life and the unconscious mind. London: Karnac.

Cytrynbaum, S., \& Noumair, D.A. (2004). Group dynamics, organisational irrationality, and social complexity: Group relations reader 3. Jupiter, FL: A.K. Rice Institute.

De Board, R. (2014). The psychoanalysis of organisations. A psychoanalytic approach to behaviour in groups and organisations. London: Routledge.

Dejours, C. (2015). Psychopathology of work. Clinical observations. London: Karnac.

Diamond M.A., \& Allcorn, S. (2009). Private selves in public organisations. The psychodynamics of organisational diagnosis and change. New York, NY: Palgrave MacMillan.

Emewu, I. (2013). 8 months on, 14 federal CEO's still acting. The Sun. Retrieved from https://www.sunnewsonline.com

French, R., \& Simpson, P. (2015). Attention, cooperation, purpose. An approach to working in groups using insights from Wilfred Bion. London: Karnac.

Gaitanidis, A., \& Curk, P. (2007). Narcissism. A critical reader. London: Karnac.

Gergen, K.J., Josselson, R., \& Freeman, M. (2015). The promises of qualitative inquiry American Psychologist, 70(1), 1-9. https://doi.org/10.1037/a0038597

Goldman, A. (2008). Company on the couch: Unveiling toxic behaviour in dysfunctional organisations. Journal of Management Inquiry, 17(3), 226-237. https://doi. org/10.1177/1056492608318157
Gould, L.J., Lucey, A., \& Stapley, L. (2011). The reflective citizen. Organisational and social dynamics. London: Karnac.

Graneheim, U.H., \& Lundman, B. (2003). Qualitative content analysis in nursing research: Concepts, procedures and measures to achieve trustworthiness. Nurse Education Today, 24(2), 105-112. https://doi.org/10.1016/j.nedt.2003.10.001

Hirschhorn, L. (1997). Reworking authority: Leading and following in the post-modern organisation. London: MIT Press.

Hirschhorn, L. (2018). Beyond BART (boundaries, authority, role and task): Creative work and the development project. Organisational and Social Dynamics, 18(1), 41-61. https://doi.org/10.2139/ssrn.2896815

Hodgkinson, G.P., \& Sparrow, P.R. (2002). The competent organisation. A psychological analysis of the strategic management process. Buckingham: Open University Press.

Huffington, C., Armstrong, A., Halton, W., Hoyle, L., \& Pooley, J. (2004). Working below the surface: The emotional life of contemporary organisations. London: Karnac.

Johnson, R., \& Waterfield, J. (2004). Making words count: The value of qualitative research. Physiotherapy Research International, 9(3), 121-131. https://doi. org/10.1002/pri.312

Kets De Vries, M.F.R., Korotov, K., \& Florent-Treacy, E. (2007). Coach and couch: The psychology of making better leaders. Hampshire: Palgrave Macmillan.

Layton, L., \& Leavy-Sperounis, M. (2020). Towards a social psychoanalysis. Culture, character, and normative unconscious processes. London: Routledge.

Lewis, H.B. (1971). Shame and guilt in neurosis. New York, NY: International Universities Press.

Lipman-Blumen, J. (2005). The allure of toxic leaders. New York, NY: Oxford University Press.

Long, S. (2013). Socioanalytic methods. Discovering the hidden in organisations and social systems. London: Karnac.

Lubit, R. (2004). Coping with toxic managers, subordinates, and other difficult people. Upper Saddle River, NJ: Financial Times Prentice Hall.

Newton, J., Long, S., \& Sievers, B. (2006). Coaching in depth: The organizational role analysis method. London: Karnac.

Obholzer, A., \& Roberts, V.Z. (1994). The unconscious at work: Individual and organizational stress in human services. London: Routledge.

Prior, V., \& Glaser, D. (2006). Understanding attachment and attachment disorders. Theory, evidence and practice. London: Jessica Kingsley Publishers.

Republic of South Africa. (1994). Public service regulations 2001 in public service Act of 1994. Pretoria: Department of Public Service and Administration (DPSA) Retrieved from https://www.dpsa.gov.za

Ross, M., \& Gerstenzang, J. (1989). Bush criticized for failing to fill more than 100 high level jobs. Los Angeles Times. Retrieved from https://www/google.co. $\mathrm{za} / \# \mathrm{q}=$ Los+Angeles+Times

Sekaran, U., \& Bougie, R. (2018). Research methods for business. A skill building approach. New York, NY: Wiley.

Shapiro, E.R. (2020). Finding a place to stand. Developing self-reflective institutions, leaders and citizens. Bicester: Phoenix.

Sher, M. (2013). The dynamics of change. Tavistock approaches to improving socia systems. London: Karnac.

Sher, M. (2017). Redundancy kills. The Tavistock Institute. Retrieved from https:// www.tavinstitute.org/projects/redundancy-kills/

Sikora, P., Moore, S., Greenberg, E., \& Grunberg, L. (2008). Downsizing and alcohol use. A cross-lagged longitudinal examination of the spillover hypothesis. Work \& Stress, 22(1), 51-68. https://doi.org/10.1080/02678370801999651

Sitlington, H., \& Marshall, V. (2011). Do downsizing decisions affect organisational knowledge and performance? Management Decision, 49(1), 116-129. https:// doi.org/10.1108/00251741111094473

Soni, Y.P. (2016). Organizational restructuring. London: Xlibris Publishing.

Steiner, H., \& Hall, R. (2017). Your secret mind. Getting to know and living with your unconscious. London: Karnac.

Syed, S. (2010). Impact of organizational restructuring on psychological contract breach and attitudes of employees working in private commercial banks of Pakistan. Unpublished master's dissertation in Business Administration, University of Twente.

Terre'Blanche, M., Durrheim, K., \& Painter, D. (2006). Research practice. Applied methods for social sciences. Cape Town: UCT Press.

Thorne, S. (2016). Interpretive description. Qualitative research for applied practice. New York, NY: Routledge.

Thorne, S. (2020). Beyond theming: Making qualitative studies matter. Nursing Inquiry, 27(1), e12343. https://doi.org/10.1111.nin.12302

Van Niekerk, E. (2011). The systems psychodynamic world of the fund manager. PhD thesis, UNISA, Pretoria.

Viljoen, R. (2015). Organisational change and development. An African perspective. Randburg: Knowres.

Wangithi, W.E., \& Muceke, N.J. (2012). Effect of human resources management practices on psychological contract in organisations. International Journal of Business and Social Sciences, 3(19), 117-122.

White, S. (2013). An introduction to the psychodynamics of workplace bullying. London: Karnac.

Wilson, S., \& MacLean, R. (2011). Research methods and data analysis for psychology. London: McGraw-Hill.

Winnicott, D.W. (1965). The maturational process and the facilitating environment. Studies in the theory of emotional development. New York, NY: International Universities Press. 